\title{
Production dynamics of some arctic Chironomus larvae
}

\author{
Malcolm G. Butler \\ Division of Biological Sciences, University of Michigan, Ann Arbor 48109
}

\begin{abstract}
Production and standing stock were determined for a two-species population of Chironomus larvae in a tundra pond near Barrow, Alaska, from 1975 through 1977. These larvae take 7 years from recruitment to adult emergence, and a multicohort population was always found. Cohort-specific values for standing stock and annual production were calculated from size and abundance data for seven cohorts found in each sample. Total standing stock ranged from 6.7 to $12.3 \mathrm{~g} \cdot \mathrm{m}^{-2}$ (dry wt), and total annual production values were $5.4,3.6$, and $3.4 \mathrm{~g} \cdot \mathrm{m}^{-2}$ in the 3 years. Low temporal variation in both standing stock and annual production results from the multicohort structure of the population.

Life table methods were used to estimate a value of $4.5 \mathrm{~g} \cdot \mathrm{m}^{-2}$ for cohort production over a 7-year life cycle. Cohort $P: B$ was 3.6, which is typical for Chironomus. Annual $P: B$ values averaged only 0.49 because annual standing stock is about scven times greater than average cohort biomass over the life cycle, while annual production is comparable to cohort production.
\end{abstract}

Estimates of secondary production by aquatic macroinvertebrates depend on a knowledge of life history characteristics. For any population, it is necessary to know something about abundance, growth, mortality, and the duration of the life cycle. The size-frequency (Hynes) method (Waters and Hokenstrom 1980; Hynes 1980) is often used when these parameters cannot be measured directly by following discrete cohorts. With this method, one must make assumptions about growth pattern and longevity, and additional data are needed to correct the resulting estimate for these assumptions (Hamilton 1969; Benke 1979). In contrast, when reproduction is synchronous and cohorts can be identified, as in the example presented below, all these parameters may be estimated directly, and the influence of each variable on standing stock and the rate of production can be seen.

I describe here the production dynamics of some arctic Chironomus larvae with a 7-year life cycle and relatively synchronous annual recruitment of new cohorts. Cohort-specific data on growth and abundance are used to estimate both an-

\footnotetext{
${ }^{1}$ Present address: Department of Zoology, Stevens Hall, North Dakota State University, Fargo 58105 .
}

nual and cohort values for production and standing stock and to illustrate the influence of life history and population structure on these parameters.

This research was supported by grants from DOE to J. E. Hobbie and by the $\mathrm{H}$. H. Rackham School of Graduate Studies at the University of Michigan. Fieldwork was carried out at the Naval Arctic Research Laboratory at Barrow, Alaska. I thank S. Mozley, D. Rosenberg, D. White, and T. Waters for comments on an earlier draft of the manuscript, and J. Lehman for discussions.

\section{Methods}

Study site-The data presented were taken from Pond $J$ in the IBP Tundra Biome site at Barrow $\left(71^{\circ} 18^{\prime} \mathrm{N}, 156^{\circ} 42^{\prime} \mathrm{W}\right)$, Alaska, during the 1975, 1976, and 1977 seasons. Pond $\mathrm{J}$ is one of several described in detail by Hobbie (1980). It is small $(0.08 \mathrm{ha})$, shallow $(25-35 \mathrm{~cm})$, and has a highly organic sediment composed mostly of peat. As the pond and its sediments are frozen down to permafrost through the arctic winter, chironomid activity is restricted to a period of about 3 months, from mid-June to mid-September. Sediment-surface temperatures during this open-water season average about $6^{\circ} \mathrm{C}$, but often fluctuate $5^{\circ}-10^{\circ} \mathrm{C}$ daily and may reach $20^{\circ} \mathrm{C}$ on calm, sunny days. 
The macrobenthic fauna of these ponds is dominated by chironomid larvae (Butler et al. 1980). Here I present data from the fine sediments in the center of Pond $\mathrm{J}$, where the fauna consists primarily of Chironomus, Procladius, and Tanytarsini larvae, and a few oligochaetes. Although Tanytarsini may equal or exceed Chironomus larvae in abundance, the latter always dominate in biomass.

Life-cycle analysis-The population is comprised of two undescribed, sibling Chironomus species with ncarly identical life cycles. Both are found in the same habitat in ponds at Barrow and at Prudhoe Bay, Alaska, and can be distinguished with certainty only in the adult stage. Consequently, I treat the larvae as a single population.

Larvae were sampled by hand-coring the sediment to a depth of $10 \mathrm{~cm}$ using five $35.5-\mathrm{cm}^{2}(1975)$ or eight $17.4-\mathrm{cm}^{2}$ (1976-1977) replicates. The samples were never washed through a mesh $>70$ $\mu \mathrm{m}$, so that all four instars were sampled quantitatively. Samples were collected twice during each season: a "spring" sample soon after the thaw but before emergence of adults, and a "fall" sample as late in each season as possible.

Details of the life histories are given by Butler (1980, 1981) and Butler et al. (1980). Adults of both species emerge within a period of about 3 weeks each year. Oviposition follows emergence by a few days and eggs develop and hatch within about a week. This leads to distinct size differences between year classes through much of the life cycle.

Cohort analysis was based on larval length in instars I-III and on an index of developmental maturity in instar IV, with consideration of the timing and magnitude of adult emergence. In every sample, the length-frequency distribution for larvae $<9 \mathrm{~mm}$ long (instars I-III) showed three or four clearly disjunct size groups (Butler 1981). As these proposed year classes often differed greatly in abundance, they could be traced easily between sampling dates. In instar IV, sexual dimorphism and individual variation resulted in a nearly continuous distribu- tion of larval length on each date, but the wide range of sizes and the abundance of these larvae in each sample relative to the number of emerging adults indicated that more than one cohort was present. As larvae grow through this final instar, wing and leg primordia in the thoracic segments develop continuously (Wuelker and Goetz 1968). I used the nine developmental phases defined by Wuelker and Goetz as a categorical variable to determine the relative ages of instar IV larvae in each sample. Instar IV larvae frequently showed a trimodal distribution on this axis of relative age (Butler 1981). The presence of three slowly developing cohorts within instar IV on each date was supported by in situ growth and development studies, analysis of larval dry weight relative to sex and developmental phase, and the abundance and timing of emerging adults. Procedures used in separating and following cohorts are given by Butler $(1980,1981)$. On each of the six dates I identified four cohorts in instars I-III and three cohorts within instar IV. Size, growth, abundance, and mortality data are thus available for 10 different cohorts over different portions of the 7-year life cycle hypothesized for each cohort.

Estimation of production-Larval dry weights were calculated from data on length by regressions determined from 38 instar IV and 21 instar III larvae collected from Pond J, narcotized in carbonated water, measured to the nearest 0.5 $\mathrm{mm}$, and dried for $24 \mathrm{~h}$ at $60^{\circ} \mathrm{C}$. Individual larvae were then weighed on an electrobalance to the nearest $1.0 \mu \mathrm{g}$.

Cohort production is calculated for the interval between the spring and fall samples each year: 58,56 , and 86 days long during 1975, 1976, and 1977 (Table 1). Production is calculated according to the increment summation method (Gillespie and Benke 1979) using

$$
P=\bar{N} \Delta W
$$

where $P$ is production over a time interval, $\bar{N}$ is the mean density of larvae, and $\Delta W$ is the difference between final and initial mean larval weight. No production 
Table 1. Calculation of biomass and production of Chironomus larvae in Pond J over 3 years. Cohorts are labeled according to presumed year of recruitment. $N$-Larvae $\cdot \mathrm{m}^{-2} ; W-$ mean individual dry wt (mg); $B$-cohort biomass, $P$-production (both in $\mathrm{mg}$ dry $\mathrm{wt} \cdot \mathrm{m}^{-2}$ ).

\begin{tabular}{|c|c|c|c|c|c|c|c|c|c|c|c|}
\hline Cohort & Age & $N$ & W & $B$ & $N$ & $w$ & $B$ & $\bar{N}$ & $\Delta W$ & $P$ & $\begin{array}{c}\text { Season } P \\
(90 \mathrm{~d})\end{array}$ \\
\hline & & \multicolumn{3}{|c|}{5 Jul 75} & \multicolumn{3}{|c|}{1 Sep 75} & \multicolumn{3}{|c|}{ 58-d interval } & \\
\hline 1968 & 7 & 340 & 5.75 & 1,956 & & & & - & - & - & - \\
\hline 1969 & $6-7$ & 1,078 & 4.60 & 4,962 & 908 & 3.44 & 3,127 & 993 & -1.28 & - & - \\
\hline 1970 & $5-6$ & 1,985 & 2.24 & 4,442 & 964 & 3.94 & 3,797 & 1,475 & 1.70 & 2,509 & 3,893 \\
\hline 1971 & $4-5$ & 1,191 & 0.42 & 501 & 624 & 1.12 & 700 & 908 & 0.70 & 636 & 987 \\
\hline 1972 & $3-4$ & 1,815 & 0.20 & 359 & 1,645 & 0.33 & 542 & 1,730 & 0.13 & 227 & 353 \\
\hline 1973 & $2-3$ & 340 & 0.03 & 8 & 170 & 0.11 & 18 & 255 & 0.08 & 21 & 33 \\
\hline 1974 & $1-2$ & 8,396 & $<0.01$ & 27 & 3,177 & 0.02 & 64 & 5,787 & $<0.02$ & 98 & 152 \\
\hline 1975 & 1 & & & & 0 & - & - & 0 & - & - & - \\
\hline \multirow[t]{2}{*}{ Total } & & & & 12,255 & & & 8,248 & & & 3,491 & 5,417 \\
\hline & & \multicolumn{3}{|c|}{23 Jun 76} & \multicolumn{3}{|c|}{18 Aug 76} & \multicolumn{3}{|c|}{ 56-d interval } & \\
\hline 1969 & 7 & 795 & 3.94 & 3,132 & & & & - & - & - & - \\
\hline 1970 & $6-7$ & 651 & 5.35 & 3,481 & 360 & 5.48 & 1,973 & 506 & 0.13 & 67 & 108 \\
\hline 1971 & $5-6$ & 219 & 2.24 & 490 & 865 & 4.26 & 3,686 & 542 & 2.02 & 1,097 & 1,761 \\
\hline 1972 & $4-5$ & 940 & 0.47 & 444 & 1,441 & 1.16 & 1,675 & 1,191 & 0.69 & 821 & 1,319 \\
\hline 1973 & $3-4$ & 144 & 0.12 & 17 & 0 & - & - & - & - & - & - \\
\hline 1974 & $2-3$ & 4,179 & 0.03 & 125 & 1,369 & 0.12 & 166 & 2,774 & 0.09 & 253 & 406 \\
\hline 1975 & $1-2$ & 219 & $<0.01$ & $<1$ & 1,369 & 0.04 & 49 & 794 & 0.03 & 26 & 42 \\
\hline 1976 & 1 & & & & 2,522 & $<0.01$ & 3 & - & - & - & - \\
\hline \multirow[t]{2}{*}{ Total } & & & & 7,690 & & & 7,552 & & & 2,263 & 3,636 \\
\hline & & \multicolumn{3}{|c|}{18 Jun 77} & \multicolumn{3}{|c|}{12 Sep 77} & \multicolumn{3}{|c|}{ 86-d interval } & \\
\hline 1970 & 7 & 216 & 6.18 & 1,335 & & & & - & - & - & - \\
\hline 1971 & $6-7$ & 432 & 4.96 & 2,145 & 432 & 5.22 & 2,254 & 432 & 0.25 & 109 & 114 \\
\hline 1972 & $5-6$ & 1,369 & 2.11 & 2,882 & 1,152 & 4.15 & 4,783 & 1,261 & 2.05 & 2,579 & 2,699 \\
\hline 1973 & $4-5$ & 216 & 0.39 & 84 & 144 & 1.20 & 173 & 180 & 0.82 & 147 & 154 \\
\hline 1974 & $3-4$ & 1,081 & 0.19 & 203 & 967 & 0.40 & 391 & 1,024 & 0.22 & 222 & 232 \\
\hline 1975 & $2-3$ & 1,585 & 0.04 & 57 & 720 & 0.16 & 116 & 1,153 & 0.13 & 144 & 150 \\
\hline 1976 & $1-2$ & 1,441 & $<0.01$ & 5 & 1,801 & 0.03 & 54 & 1,621 & 0.03 & 43 & 45 \\
\hline 1977 & 1 & & & & 216 & $<0.01$ & $<1$ & - & - & - & - \\
\hline Total & & & & 6,710 & & & 7,771 & & & 3,244 & 3,395 \\
\hline
\end{tabular}

is calculated for cohorts showing a decrease in mean individual weight during an interval, or for those not represented on one of the two sampling dates. Production of biomass is assumed to occur at a constant rate from thaw to freeze, and the value calculated for an actual sampling interval, when normalized to a standard 90-day season, is considered annual production.

Another approach is used to illustrate the pattern of production over the entire life cycle of a typical cohort of these Chironomus larvae. Size and abundance data are available for 10 different cohorts over various portions of the life cycle (Butler 1981) and age-specific values for larval size and abundance are summarized, using a combination of age-specific and time-specific life table techniques (Southwood 1978), to construct a life table for a "composite cohort." Age is assigned each winter, so fall and spring values are averaged for cohorts sampled both immediately before and immediately after a given winter; single values from cohorts sampled only once (fall or spring) at a given age are also used to generate each mean value. Four independent cohorts contribute to each age-specific value of weight or abundance for the composite cohort. Cohort production is calculated algebraically from increment summation over ages $1-7$.

\section{Results}

Length-weight relationships-Newly hatched larvae are about $1 \mathrm{~mm}$ long and 


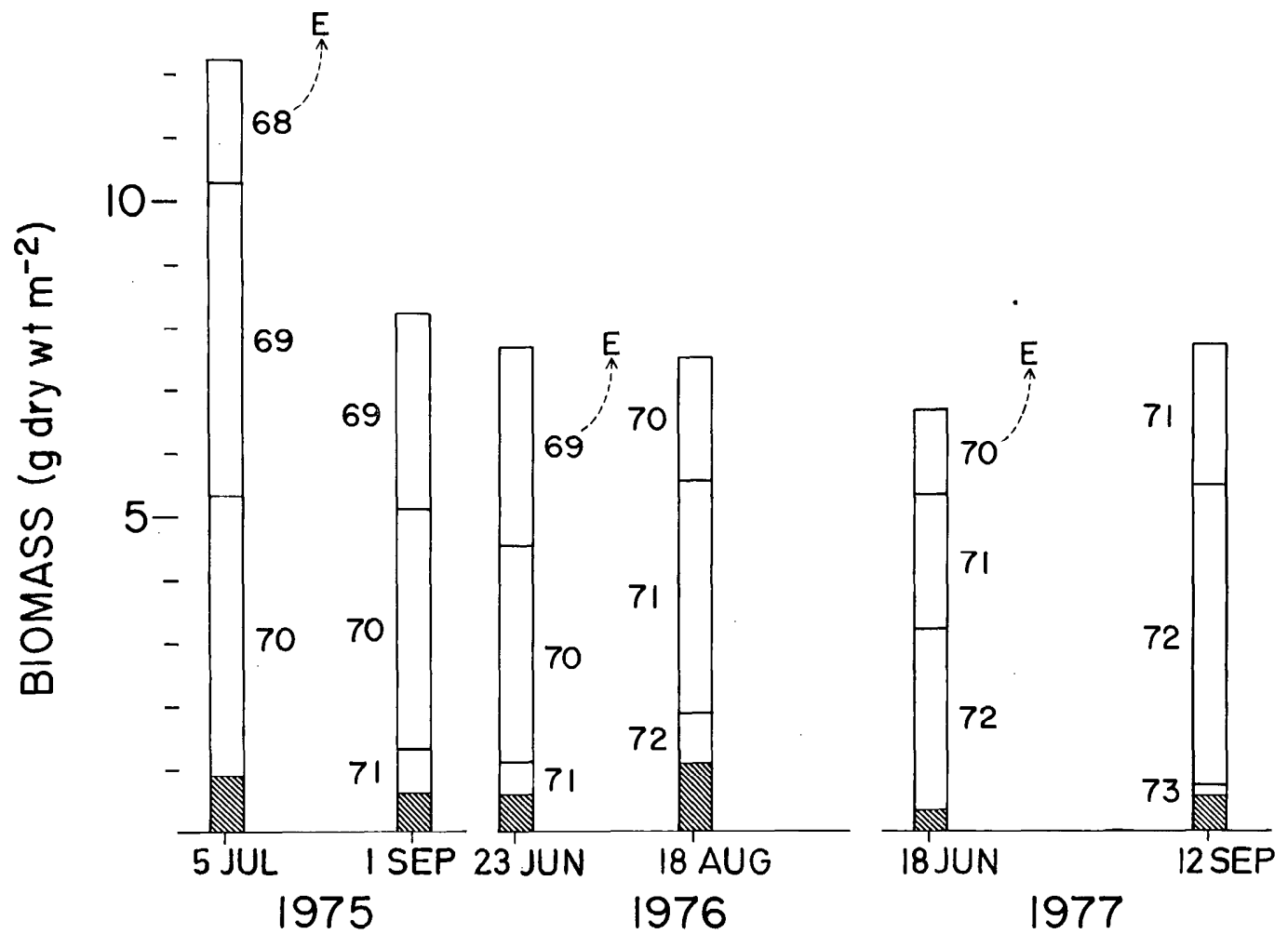

Fig. 1. Standing stock of Chironomus larvae in Pond J. Three instar IV cohorts (labeled by year of recruitment) are present on each date; hatched portion represents biomass of four younger cohorts in instars I, II, and III. One cohort emerges each summer (E).

grow to about $2 \mathrm{~mm}$ before molting early in their second summer. Over the next year, the instar II larvae range from about 2.5 to $4.0 \mathrm{~mm}$ and weigh $<0.1 \mathrm{mg}$. During the 2 years in instar III, larvae grow from about $5 \mathrm{~mm}$ to $8-9 \mathrm{~mm}$ and increase in dry weight from about $0.1 \mathrm{mg}$ to $0.5-0.6$ mg. Newly molted instar IV larvae are about $10 \mathrm{~mm}$ long, and over the next 2 years they grow to around $3 \mathrm{mg}$ for male larvae and as much as 5-6 $\mathrm{mg}$ for females. There seems to be little weight increase over the final year, but considerable prepupal development.

Separate regressions were determined for instars III and IV to maximize the fit in the larger instar, whose larvae contribute most to both standing stock and production. The instar IV relationship is

$$
\ln W=4.15 \ln L-10.06
$$

where $W$ is dry weight (in $\mathrm{mg}$ ) and $L$ is total body length (in $\mathrm{mm}$ ). This relationship explains $93 \%$ of the variance in individual weight among the 38 instar IV larvae. The instar III relationship is

$$
\ln W=3.07 \ln L-7.18
$$

which explains $72 \%$ of the variance among the 21 larvae measured. This latter relationship is used to estimate weights for larvae in instars I and II.

Standing stock-Most of the total Chironomus biomass in every sample is contributed by three coexisting cohorts in instar IV (Fig. 1). A major loss of biomass occurs when one of these cohorts emerges each year, yet another cohort soon molts from instar III to instar IV. Each cohort's contribution to total standing stock depends on its abundance and the average weight of an individual larva. Cohort abundance is much more variable than is larval size at a given age (Butler 1981), 
and biomass of individual cohorts varies accordingly. Average standing stock over the 3-year period was $8.4 \mathrm{~g}$ dry $\mathrm{wt} \cdot \mathrm{m}^{-2}$ and the coefficient of variation among the six sampling dates was only $24 \%$, reflecting relatively low variation both within each season and from year to year.

Annual production-Total annual production of Chironomus larvae ranged from 3.4 to $5.4 \mathrm{~g} \mathrm{dry} \mathrm{wt} \cdot \mathrm{m}^{-2}$ over the 3 years (Table 1$)$. These values are higher than previously published estimates of Chironomus production in Pond $\mathrm{J}$ over the same years (Butler et al. 1980), because a more realistic length-weight relationship is used here. Eight different cohorts were present within each season, but only five or six contributed significantly to annual production each ycar. There was no growth before emergence during the last summer, hence no production is calculated for these cohorts. Larvae also appeared to gain little or no weight over their sixth and final complete summer (Butler 1981). The weight data in Table 1 are based on measurements of mean larval length, which showed a slight increase for only two of the three cohorts observed over their penultimate summer. Weight gain by instar I larvae between hatching and their appearance in the fall sample was not measured directly, but was probably $<1 \mu \mathrm{g}$. Even at the highest cohort abundance encountered $\left(8,396 \cdot \mathrm{m}^{-2}\right)$ this would make a negligible contribution to total Chironomus production, hence production is not calculated for newly recruited cohorts.

Annual production by each cohort depends on its age and abundance. Larvae gained substantial weight during their fourth and fifth years when they grew from late instar III through the middle of instar IV, and highest production resulted from cohorts that showed high abundance at this stage of the life cycle. The cohort recruited in 1973 was poorly represented in Pond $\mathrm{J}$ throughout the study. These larvae grew normally during the 1977 sampling interval, increasing their mean individual weight by $0.82 \mathrm{mg}$, but mean cohort abundance of only $180 \cdot \mathrm{m}^{-2}$ resulted in production of only slightly more than $0.15 \mathrm{~g}$ dry $\mathrm{wt} \cdot \mathrm{m}^{-2}$ during this season. The 1971 and 1972 cohorts passed through the same portion of the life cycle in 1975 and 1976 and showed similar gains in mean larval weight. However, these cohorts averaged about 1,000 larvae $\cdot \mathrm{m}^{-2}$ at this age, and contributed around $1 \mathrm{~g}$ dry $\mathrm{wt} \cdot \mathrm{m}^{-2}$ to each year's total.

Cohort production-A life table summarizing age-specific abundance and weight data from the 10 cohorts found reflects the growth and mortality schedules a typical cohort would experience through its entire 7-year life cycle (Table 2). The composite growth schedule is sigmoid, showing a rapid weight increase between years 4 and 6 , followed by little or none during the final year. Mean individual weights of the four independent cohorts sampled at each age always varied less than twofold, indicating reasonable constancy to the growth pattern. The composite mortality schedule may be less realistic, as abundance at each age is a function both of mortality and of initial density at recruitment of each cohort. The wide range of abundance at each age probably indicates high variation in the latter variable. If comparable strength at recruitment is assumed for each cohort, the resulting mortality schedule suggests low survivorship until year 3 , little mortality between ages 3-6 years, and finally an abrupt drop in abundance over the final year. This pattern is consistent with the expected susceptibility of different instars to invertebrate predators and parasites, known causes of larval mortality (Butler 1980).

Production by this composite cohort between ages 1 and 7 years is $4.54 \mathrm{~g}$ dry $\mathrm{wt} \cdot \mathrm{m}^{-2}$. As one would expect, this is very close to $4.1 \mathrm{~g}$, the average estimate of total Chironomus production each year, as seven simultaneous cohorts can produce in 1 year what a single cohort produces in 7 years. A cohort production to biomass value $(P: B)$ of 3.6 is obtained by dividing $4.54 \mathrm{~g}$ by $1.25 \mathrm{~g}$-the mean biomass of the composite cohort between ages 1-7. Table 3 lists six other values of annual production and cohort $P: B$ for 
Table 2. Composite life table showing mean individual weight $(W)$, No. $\cdot \mathrm{m}^{-2}(N)$, biomass $(B)$, and production $(P)$ for an average cohort over 7-year lifespan.

\begin{tabular}{|c|c|c|c|c|c|}
\hline \multirow[b]{2}{*}{ Age } & \multirow[b]{2}{*}{ Instar } & \multirow{2}{*}{$\begin{array}{c}\text { Mean } W \text { (range) } \\
\text { (mg dry wt) }\end{array}$} & \multirow[b]{2}{*}{ Mean $N$ (range) } & $\bar{B}$ & $P$ \\
\hline & & & & \multicolumn{2}{|c|}{$\left(\mathrm{mg}\right.$ dry wt $\left.\cdot \mathrm{m}^{-2}\right)$} \\
\hline 1 & I & $0.003(0.002-0.004)$ & $2,676(110-8,369)$ & 6.8 & \\
\hline 2 & II & $0.028(0.020-0.036)$ & $1,824(340-3,678)$ & 51.6 & 58.0 \\
\hline 3 & III & $0.145(0.107-0.198)$ & $979(157-1,815)$ & 141.6 & 163.1 \\
\hline 4 & III & $0.400(0.329-0.473)$ & $882(108-1,293)$ & 351.1 & $\begin{array}{l}134.0 \\
1244\end{array}$ \\
\hline 5 & IV & $1.600(1.122-2.238)$ & $989(144-1,985)$ & $1,582.4$ & $\begin{array}{l}1,124.4 \\
07908\end{array}$ \\
\hline 6 & IV & $4.530(3.636-5.347)$ & $921(649-1,153)$ & $4,172.1$ & $2,798.2$ \\
\hline \multirow[t]{2}{*}{7} & IV & $4.900(3.260-5.893)$ & $478(288-852)$ & $2,342.2$ & \\
\hline & & & $\begin{array}{r}\text { Mean coh } \\
\text { Coh }\end{array}$ & $\begin{array}{l}=1.25 \mathrm{~g} \cdot \mathrm{r} \\
=4.54 \mathrm{~g} \cdot \mathrm{r}\end{array}$ & \\
\hline
\end{tabular}

Chironomus populations from a wide variety of habitats. Cohort $P: B$ values average 3.6, and range only from 3.2 to 3.9 despite a wide range of annual production values and life-cycle patterns.

\section{Discussion}

In any population, the standing stock of an individual cohort will vary over the life cycle according to the cohort's growth and mortality schedules. When cohorts overlap, the resultant standing stock may show lower temporal variation than would a population consisting of a single cohort. This is the major reason for the relative constancy of total Chironomus biomass observed throughout this study.

This might be the carrying capacity for Chironomus biomass in this pond, and interactions between cohorts might maintain total standing stock below this limit through altered growth or mortality rates. I tested this hypothesis by comparing the observed variance in standing stock over the six dates with the variance expected from random combinations of seven age classes. Because the observed variance was not significantly lower than that of the random model ( $F$-test, $P<0.001)$, I reject the hypothesis that total biomass is regulated by interactions between cohorts. Also, growth and mortality rates show no indication of density dependence.

Both the seasonal and year-to-year stability of standing stock permitted by this life cycle provide a relatively dependable food resource for predators that feed on thesc larvac. Waterfowl are the only vertebrate predators in these ponds, and their high mobility may allow them to concentrate their feeding in ponds which have high densities of instar IV larvae. A square kilometer may contain over 100 discrete ponds, and many should have a

Table 3. Annual production $\left(\mathrm{g}\right.$ dry $\left.\mathrm{wt} \cdot \mathrm{m}^{-2}\right)$ and life-cycle production to biomass ratio $(P: B)$ for Chironomus larvae.

\begin{tabular}{|c|c|c|c|c|}
\hline Species & $\underset{P}{A n n u a l}$ & $\begin{array}{c}\text { Cohort } \\
P: B\end{array}$ & Location & Reference \\
\hline C. anthracinus & 25.7 & 3.9 & Loch Leven, Scotland & Charles et al. 1974 \\
\hline C. anthracinus & 12.9 & 3.8 & L. Esrom, Denmark & Jonasson 1972 \\
\hline C. anthracinus & $1.3-3.4$ & $3.6-3.9$ & $\begin{array}{l}\text { L. Memphremagog, } \\
\text { Quebec-Vermont }\end{array}$ & Dermott et al. 1977 \\
\hline C. attenuatus & 2.8 & 3.5 & Hudson R. estuary, New York & Menzie 1978 \\
\hline C. islandicus & 6.7 & 3.4 & L. Myvatn, Iceland & Lindegaard and Jonasson 1979 \\
\hline C. plumosus & 3.5 & 3.2 & Reservoir Wales & Potter and Learner 1974 \\
\hline Chironomus spp. & 4.1 & 3.6 & Tundra pond, Alaska & Present study \\
\hline
\end{tabular}


large Chironomus standing stock even if recruitment is highly variable in some years.

Substantial contributions by several independent cohorts also help stabilize total annual production from fluctuations caused by low abundance of any individual cohort. Each year the two cohorts between ages 4 and 6 years contributed at least $85 \%$ of the annual Chironomus production. Individually, however, production by these six potentially dominant cohorts ranged from as low as 0.15 to as high as $3.89 \mathrm{~g}$ dry $\mathrm{wt} \cdot \mathrm{m}^{-2}$. Because five or six cohorts contribute to each season's total, the coefficient of variation for annual production was only $27 \%$ over the 3 years. This temporal stability is particularly significant in that Chironomus larvae dominate macrobenthic production here. Two Tanytarsus species are the only other abundant detritivores in the center of Pond $\mathrm{J}$, and their average annual production over the 3 years was only $8 \%$ that of Chironomus (Butler 1980).

This population structure also influences the way in which annual production should be calculated. Gillespie and Benke (1979) have shown the algebraic equivalence of the increment summation and removal summation methods when production is calculated over the entire life cycle of a single cohort. When only a portion of a cohort's lifespan is considered, some biomass produced may be removed through mortality during the same period, while some may accumulate to be lost through future mortality and emergence. When a multicohort population with overlapping year classes is considered, the sum of biomass removals from each cohort can be taken as an estimate of annual production only if cohort stability, in terms of abundance, mortality, and biomass, can be assumed (Waters 1977). In this example, considerable biomass produced in previous years by the 1968,1969 , and 1970 cohorts was removed by emergence and mortality during 1975 and 1976. This removal exceeded the production of new biomass by about $65 \%$ in those 2 years, but was $34 \%$ lower than annual production in 1977.
Because such a lack of equilibrium between cohorts is probably common, the removal summation method is most appropriate when production is measured over the entire life cycle of a single cohort, or when the study period greatly exceeds the generation time. Increment summation is an appropriate method in any circumstance, as it estimates production within any interval directly without assuming biomass equilibrium.

A long life cycle and slow growth by individual cohorts need not limit the productivity of the population. Here, average annual production is equivalent to life-cycle production of a typical cohort because high biomass is maintained by the fact that up to seven cohorts are growing simultaneously. This situation may not always hold, as illustrated by the hemivoltine population of Chironomus anthracinus in profundal Lake Esrom in Denmark (Jonasson 1972) where behavioral interference between cohorts precludes the establishment of overlapping generations and limits annual production to a value lower than total cohort production.

Waters (1969) suggested that the ratio of cohort production to average biomass $(P: B)$ is typically in the range $2.5-5.0$ for aquatic insects. Chironomus populations seem to vary over a much narrower range-about 3-4. Both Waters (1969, 1977) and Mathews (1970) have noted that the instantaneous growth rate equation for calculating production,

$$
P=G \times B
$$

where $G$ is the instantaneous rate of biomass production, implies that

$$
P: B=G \text {. }
$$

This relationship will hold as long as growth and mortality are constant exponential functions throughout the life span (Gillespie and Benke 1979). Waters (1969, 1977) and Mathews (1970) have suggested the use of $G$, determined from

$$
G=\ln \max w t-\ln \min w t
$$

to estimate life-cycle production from mean standing stock over the cohort's 
lifespan. A value of $G=7.6$ is obtained for the Chironomus larvae in this study, and values calculated from Chironomus minimum and maximum weights given by Jonasson (1972) and Lindegaard and Jonasson (1979) are 7.0 and 8.3-9.0. Comparison with the empirically derived cohort $P: B$ values in Table 3 shows that production would be overestimated roughly twofold using $G$ values.

The reason for the discrepancy is not clear. Waters (1969) suggested that low mortality could reduce $P: B$ relative to $G$, and that may be true in this example. But the other Chironomus populations in Table 3 all experience some degree of fish predation, yet all have a life-cycle $P: B$ close to 3.6 and well below 7. Whether this is coincidental or indicative of some uniformity in Chironomus growth and mortality patterns warrants further investigation.

Annual $P: B$, based on annual production divided by annual mean standing stock, is potentially more useful for estimating annual production (Waters 1977, 1979). The relationship between cohort $P: B$ and annual $P: B$ depends on the life cycle, as voltinism affects annual values of both production and mean standing stock. In general, the two ratios should be similar for univoltine populations. Multivoltine populations will generate several cohorts' production in a year while mean standing stock is equal to or less than average cohort biomass (Benke 1979; Waters 1979), thus annual $P: B$ will be greater than cohort $P: B$. As noted above, annual production will not necessarily decrease when life cycles exceed 1 year if annual recruitment results in overlapping cohorts. However, the resulting accumulation of biomass will depress annual $P: B$ relative to cohort $P: B$. During the 3 years of my study annual $P: B$ values were $0.47,0.48$, and 0.52 , or about one-seventh of the cohort $P: B$ value of 3.6, as a result of an average annual standing stock $(8.4 \mathrm{~g})$ seven times greater than mean cohort biomass $(1.2 \mathrm{~g})$.

This population structure is similar to that which might be expected in a totally nonseasonal environment. Here the du- ration of the life cycle (7 years) greatly exceeds the frequency of recruitment (1 year); a similar situation might also occur in a population with continuous recruitment and a very short life cycle. In both cases the age structure at any time provides an estimate of a typical cohort's life history (assuming equilibrium between recruitment and mortality). A time-specific life table can thus be constructed from the abundances of the different age classes on a single date. This is essentially the procedure used in the size-frequency method of estimating annual production (Hynes and Coleman 1968; Hamilton 1969; Hynes 1980). However, because most temperate zone populations show some degree of temporal synchronization, the entire season must be sampled so that all life-cycle stages are measured. In the size-frequency method, an average distribution of abundance over these life-cycle stages (size or age classes) is then generated to approximate the mortality schedulc. Corrections must be made if the size classes used do not correspond to true age classes (Hamilton 1969; Benke 1979). In the Pond J Chironomus population, the distribution of larvae among age classes on any date by itself provides estimates of both growth and mortality patterns over the life cycle of an "average cohort." In fact, the six independent, time-specific data sets in Table 1 can each be used to calculate lifecycle production algebraically by using increment summation. These six estimates range from $1.9-5.9 \mathrm{~g}$ dry $\mathrm{wt} \cdot \mathrm{m}^{-2}$ and average $4.2 \mathrm{~g}$, very close to both the life-cycle production of $4.54 \mathrm{~g}$ calculated from the composite cohort and the average annual production of $4.1 \mathrm{~g}$.

No method can provide a realistic estimate of production without a knowledge of the basic life history parameters, including patterns of mortality and growth and the duration of various lifecycle stages. Mortality can be estimated by the size-frequency technique, and growth pattern can often be assumed from size data and from experience without introducing serious errors to the production estimate (Hamilton 1969; Benke 
and Waide 1977). But accurate knowledge of the duration of productive stages is critical for cohort methods and especially for the size-frequency method (Benke 1979). Benke also noted that data on emergence periodicity may often be insufficient for determining the cohort production interval. This is especially true with multicohort populations where the interval between emergence periods is shorter than the length of the lifespan. In such cases, which may prove to be common in arctic, subarctic, and profundal populations, detailed cohort analysis is necessary to determine the duration of the life cycle. As such an analysis will usually also provide sufficient data on other life history parameters to permit estimation of production by more direct and accurate means, the size-frequency method may have limited utility in these habitats.

\section{References}

BENKE, A. C. 1979. A modification of the Hynes method for estimating secondary production with particular reference for multivoltine populations. Limnol. Oceanogr. 24: 168-170.

—, AND J. B. WAIDE. 1977. In defense of avcrage cohorts. Freshwater Biol. 7: 61-63.

BUTLER, M. G. 1980. The population ecology of some arctic Alaskan Chironomidae (Diptera). Ph.D. thesis, Univ. Michigan. 157 p.

- 1981. A seven-year life cycle for two Chironomus species in arctic Alaskan tundra ponds (Diptera: Chironomidae). Can. J. Zool. 60: 5870.

, M. C. Miller, and S. C. Moziey. 1980. Macrobenthos, p. 297-339. In J. E. Hobbie [ed.], Limnology of tundra ponds: Barrow, Alaska. Dowden, Hutchinson, and Ross.

Charles, W. N., K. East, D. Brown, M. C. Gray, AND T. D. MURRAY. 1974. The production of larval Chironomidae in the mud at Loch Leven, Kinross. Proc. R. Soc. Edinb. Ser. B 74: 241258.

DermotT, R. M., J. KalFF, W. C. LegGetT, AND J. SPENCE. 1977. Production of Chironomus, Procladius, and Chaoborus at different levels of phytoplankton biomass in Lake Memphremagog, Quebec-Vermont. J. Fish. Res. Bd. Can. 34: 2001-2007.
Gillespie, D. M., AND A. C. Benke. 1979. Methods of calculating cohort production from field data-some relationships. Limnol. Occanngr. 24: $171-176$.

HAMiLTON, A. L. 1969. On estimating annual production. Limnol. Oceanogr. 14: 771-782.

HoвbIE, J. E. [ED.]. 1980. Limnology of tundra ponds: Barrow, Alaska. Dowden, Hutchinson, and Ross.

HyNES, H. B. 1980. A name change in the secondary production business. Limnol. Oceanogr. 25: 778 .

- AND M. J. Coleman. 1968. A simple method of assessing the annual production of stream benthos. Limnol. Oceanogr. 13: 569-573.

JONASSON, P. M. 1972. Ecology and production of the profundal benthos in relation to phytoplankton in Lake Esrom. Oikos 14(suppl.): $148 \mathrm{p}$.

LindegaARd, C., AND P. M. JonASSON. 1979. Abundance, population dynamics, and production of zoobenthos in Lake Myvatn, Iceland. Oikos 32: 202-227.

MATHEWS, C. P. 1970. Estimates of production with reference to general surveys. Oikos 21: 129-133.

MenZIE, C. A. 1978. Productivity of chironomid larvae in a littoral area of the Hudson River estuary. Ph.D. thesis, City Univ. New York. $127 \mathrm{p}$.

PotTer, D. W., AND M. A. Learner. 1974. A study of the benthic macroinvertebrates of a shallow eutrophic reservoir in south Wales with emphasis on the Chironomidae (Diptera); their life histories and production. Arch. Hydrobiol. 74: 186-226.

SOUTHWOOD, T. R. 1978. Ecological methods: With particular reference to the study of insect populations, 2nd rev. ed. Chapman and Hall.

Waters, T. F. 1969. The turnover ratio in production ecology of freshwater invertebrates. Am. Nat. 103: $173-185$.

- 1977. Secondary production in inland waters. Adv. Ecol. Res. 10: 91-164.

- 1979. Influence of benthos life history upon the estimation of secondary production. J. Fish. Res. Bd. Can. 36: 1425-1430.

- AND J. C. HoKenstrom. 1980. Annual production and drift of the stream amphipod Gammarus pseudolimnaeus in Valley Creek, Minnesota. Limnol. Oceanogr. 25: 700-710.

WUElKER, W., AND P. GOETZ. 1968. Die Verwendung der Imaginalscheiben zur Bestimmung des Entwicklungszustandes von ChironomusLarven (Diptera). Z. Morphol. Oekol. Tiere 62: 363-388.

Submitted: 29 December 1980 Accepted: 12 November 1981 